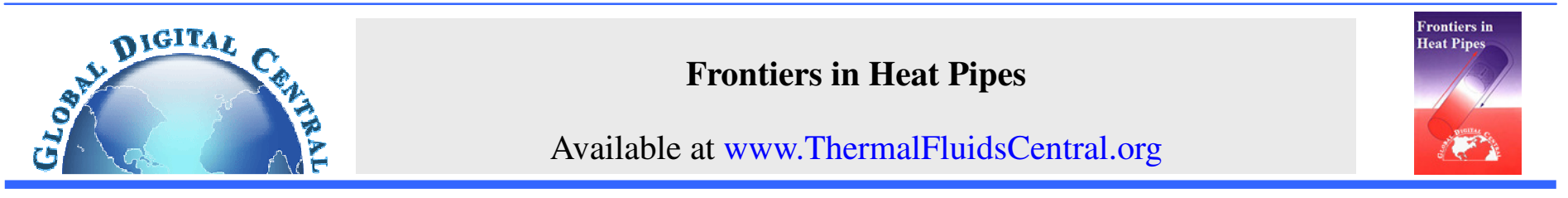

\title{
A VAPOR-PRESSURE-DRIVEN HEAT PIPE FOR SIDEWARD LONG-DISTANCE HEAT TRANSPORT
}

\author{
Yasushi Koito $^{\mathrm{a},{ }^{*}}$, Yoshitake Ikemizu ${ }^{\mathrm{a}}$, Toshio Tomimura ${ }^{\mathrm{a}}$, Masataka Mochizuki ${ }^{\mathrm{b}}$ \\ ${ }^{a}$ Department of Advanced Mechanical Systems, Kumamoto University, Kumamoto-shi, Kumamoto, 860-8555, Japan \\ ${ }^{b}$ Thermal Technology Division, Fujikura Ltd., Koto-ku, Tokyo, 135-8512, Japan
}

\begin{abstract}
An experimental study is carried out on a sideward long-distance heat transport utilizing vapor pressure of a working fluid. The present heat pipe is a closed loop, which consists of a heated section (evaporator), a cooled section (condenser), a reservoir, valves and pipes connecting these components. The experimental results confirm that the heat pipe works periodically corresponding to the valve operation, and the heat is transported sideward continuously from the heated section to the cooled section. The vapor-pressure-driven heat pipe is effective for a large-scale thermal management.
\end{abstract}

Keywords: Special heat pipe, Periodic operation, Large-scale thermal management.

\section{INTRODUCTION}

A two-phase closed thermosyphon is a typical thermal device for upward heat transport. The bottom of the thermosyphon is an evaporator section while the top is a condenser section. Since the condenser section is located above the evaporator section, the condensate is returned to the evaporator section passively by the force of gravity. The two-phase closed thermosyphon has been widely used in many industrial applications where it is required to transport heat from lower to higher positions.

A two-phase downward heat transport, on the other hand, requires lifting the condensate against the force of gravity. This type of heat pipe is referred to as "anti-gravity heat pipe" or "top-heat-type heat pipe". For the anti-gravity operation, a capillary force (Maydanik, 2005), an osmotic force (Minning et al., 1978; Minning et al., 1979; Basiulis et al., 1980) and a vapor lift pump (Chisholm, 1974; Hirashima et al., 1993) were used in the past studies. In addition, many studies were carried out on a vapor-pressure-driven anti-gravity heat pipe, where vapor pressure of a working fluid was utilized to lift the condensate against the force of gravity. As regards the vaporpressure-driven heat pipe, the experimental studies were carried out by Ogushi et al. (1986), Hashimoto et al. (1995), Kawabata et al. (1996), Fantozzi et al. (2002, 2004), Kadoguchi et al. (2004) and Filippeschi (2006). A mathematical model of the heat pipe was also presented in the paper by Filippeschi (2006) to discuss the operational characteristics. Compared with the others, the vapor-pressure-driven heat pipe is recommended for the anti-gravity heat transport because of its reliability and simplicity. However, it should be noted here that the vapor-pressure-driven heat pipe cannot be applied for the downward long-distance heat transport. This is attributed to the fact that the vapor pressure required to lift the condensate is increased with the increase in a heat transport height, causing to increase the inner temperature difference and therefore decrease the thermal conductance of the heat pipe.

This paper addresses the use of the vapor pressure of the working fluid for a sideward heat transport over a long distance. The heat transport direction is perpendicular to the gravity. Including a conventional capillary-driven heat pipe, there are many types of heat pipes known today for the sideward heat transport; however, enough data have not been published on the reliability of heat pipes when the heat transport distance is greatly increased. The vapor-pressure-driven sideward heat pipe is therefore presented in this study based on the previous studies mentioned above. The principle of operation of the heat pipe is described in detail, and the experimental results are shown on the operational characteristics.

In recent years, many studies have been carried out on a cooling of data centers (Gondipalli et al., 2009; Karajgikar et al., 2009; Patterson et al., 2009; Mochizuki et al., 2010), where not only a component level but also a system level thermal management is required for thermal engineers. The present study is thus motivated for such a large-scale thermal management.

\section{PRINCIPLE OF OPERATION}

Figure 1 shows a schematic illustration of the proposed heat pipe. The heat pipe is a closed loop, which consists of a heated section (evaporator section), a cooled section (condenser section), a reservoir, two valves (Valve 1 and Valve 2), a check valve and pipes (vapor line, liquid line etc.) connecting these components. The heated section and the cooled section are the same in height, and the reservoir is slightly higher than them. The check valve is used to prevent a reverse flow.

\footnotetext{
*Corresponding author. Email: koito@gpo.kumamoto-u.ac.jp
} 

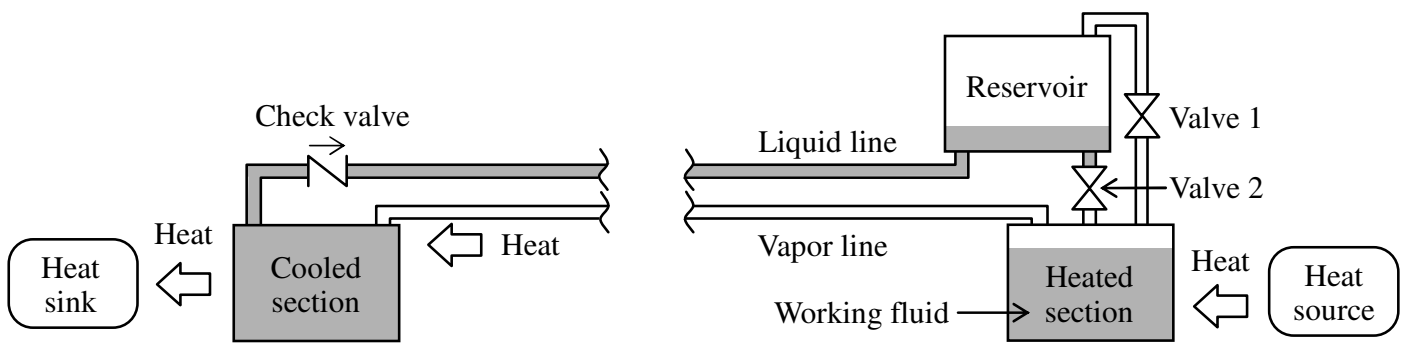

Fig. 1 Schematic illustration of proposed heat pipe

After the air is evacuated inside the heat pipe, the working fluid is charged as shown in the figure. The heat is transported sideward from the heated section to the cooled section according to the principle of operation explained as follows:

(i) Valve 1 and Valve 2 are initially closed. The heated section receives the heat from the heat source.

(ii) The liquid inside the heated section vaporizes and the vapor flows sideward through the vapor line to the cooled section, where the heat is discharged into the heat sink. The vapor condenses and the condensate is moreover subcooled in the cooled section. The accumulation of condensate decreases the area for condensation and then increases the vapor pressure inside the cooled section. The vapor pressure thus pushes the condensate through the liquid line to the reservoir, where the cooled liquid is stored.

(iii) When the heated section becomes empty, Valve 1 and Valve 2 are opened. The vapor inside the heated section flows into the reservoir, and then the cooled liquid stored inside the reservoir flows down to the heated section under the action of gravity.

(iv) Valve 1 and Valve 2 are closed. The operations of (ii), (iii), (iv) are repeated.

Corresponding to the valve operation, the heat pipe works periodically and transports the heat utilizing the latent heat of evaporation and condensation of the working fluid. It should be noted here that the pressure to push the condensate from the cooled section to the reservoir is ensured even when the heat transport distance ( $=$ the distance between the heated section and the cooled section) is very long. This is the advantage of the present heat pipe.

During the heat transport period when Valve 1 and Valve 2 are closed, there exists the following relation between the pressures inside the heated section, $P_{h}$, the cooled section, $P_{c}$, and the reservoir, $P_{r}$.

$P_{r}<P_{c}<P_{h}$

The pressure difference between the heated section and the reservoir, $P_{h}$ $-P_{r}$, is essentially a driving force to circulate the working fluid inside the heat pipe. The pressure difference between the heated section and the cooled section, $P_{h}-P_{c}$, corresponds to a vapor pressure drop due to the friction, while that between the cooled section and the reservoir, $P_{c}$ $-P_{r}$, is the sum of the two pressure drops in the liquid line due to the friction and the gravity. It should be pointed out that, in the case of the sideward heat transport, the pressure drop due to the gravity remains unchangeable against the heat transport distance. The pressure drop due to the friction is therefore an important consideration for the sideward long-distance heat transport. The effect of the pressure drop on the operational characteristics of the heat pipe will be discussed in this paper.

\section{EXPERIMENTAL APPARATUS AND}

\section{PROCEDURE}

\subsection{Experimental Apparatus}

Figure 2 shows an experimental apparatus of the present heat pipe, which mainly consists of a heated section $(1.65 \mathrm{~L})$, a cooled section $(0.38 \mathrm{~L})$, a reservoir $(1.65 \mathrm{~L})$, two valves (Valve 1 and Valve 2$)$, a check valve and pipes (vapor line, liquid line etc.) connecting these components. Both the heated section and the reservoir are made of a stainless steel pipe (inner diameter: $49.5 \mathrm{~mm}$ ) and clear polycarbonate end caps. The clear resin is used to observe the working fluid inside the heated section and the reservoir. Two copper blocks holding a cartridge heater (maximum $900 \mathrm{~W}$ ) each are attached as a heat source on the outer surface of the bottom of the heated section. The cooled section is made by coiling a copper tube having the inner diameter of $8.0 \mathrm{~mm}$ and the length of $7.37 \mathrm{~m}$. The cooled section is immersed in water in the bath, where the water temperature is controlled by using the unit shown in Fig. 3. The water in the bath is also stirred by a mixing pump. The stainless pipe having the inner diameter of $8.0 \mathrm{~mm}$ is used to connect the components. The cooled section is the same height as the heated section, while the reservoir is $400 \mathrm{~mm}$ higher than the heated section. The heat pipe is covered with a thermal insulator to reduce any heat loss. After the air is evacuated inside the heat pipe, the working fluid is charged from a fill tube with Valve 1 and Valve 2 open. In the charging process, the working fluid flows through the fill tube, the liquid line and the reservoir, and then it is stored in the heated section. Water is used as the working fluid.

The measuring points of temperatures and pressures are also indicated in Figs. 2 and 3. The liquid temperatures inside the heated section, $T_{h}$, the cooled section (outlet: $T_{c}$ ), the reservoir, $T_{r}$, the heat exchanger (inlet: $T_{H E X, \text { in }}$, outlet: $T_{H E X, \text { out }}$ ), the water bath, $T_{w}$, are measured by thermocouples. The pressure transducers are used to measure the vapor pressures inside the heated section, $P_{h}$, the vapor line (inlet: $P_{l, \text { in }}$, outlet $P_{l, \text { out }}$ ) and the reservoir, $P_{r}$. The liquid flow rate, $m$, inside the heat exchanger of the temperature control unit and the amount of heat input from each heater are measured by a flow meter and two watt meters, respectively.

\subsection{Experimental Procedure}

Two kinds of experiments termed as (A) and (B) are performed in this study. Experiment (A) is a fundamental study to investigate the operational characteristics of the present heat pipe. Experiment (B), on the other hand, aims at discussing the effect of the pressure drop inside the heat pipe on the operational characteristics. In both experiments, Valve 1 and Valve 2 are operated by hand. However, in a practical system, as described in the previous paper (Imura et al., 2003), it is recommended to use an electromagnetic switching valve and a check valve as Valve 1 and Valve 2, respectively. The former is usually closed by the force of the spring and is opened by the very small amount of the electricity, while the latter allows the fluid flow in one direction only from the reservoir to the heated section. 

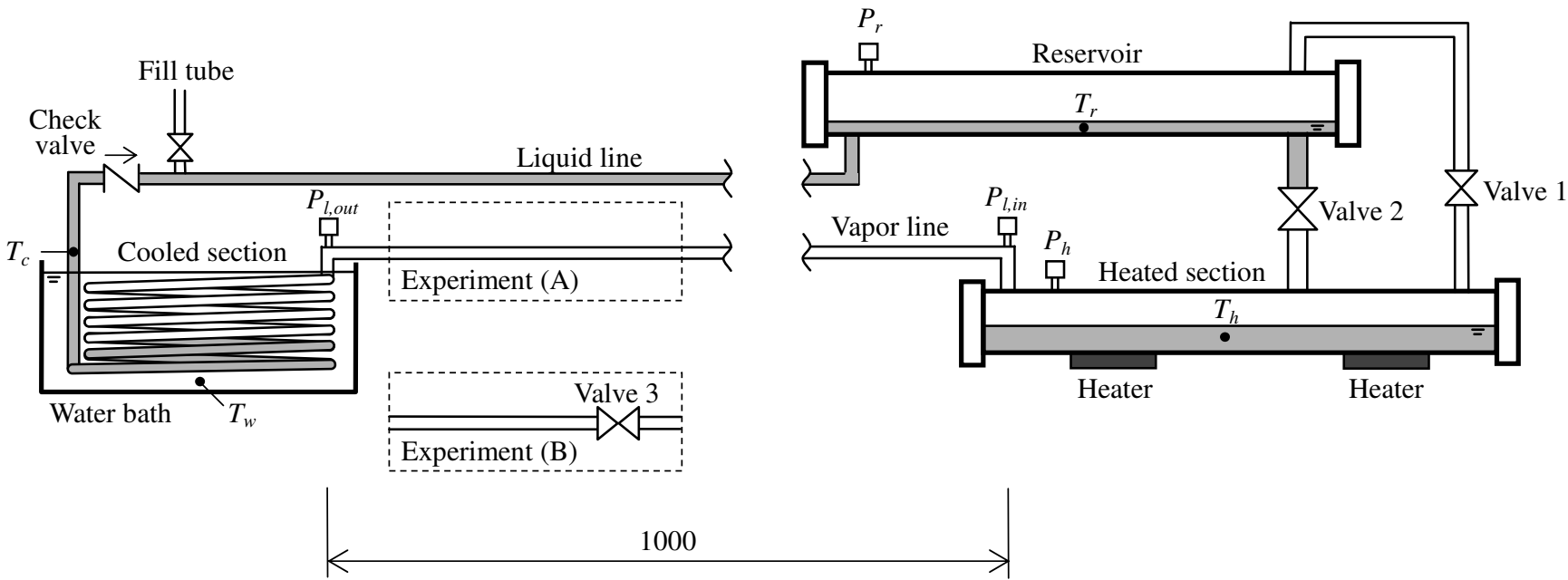

Fig. 2 Experimental apparatus

Experiment (A) According to the principle of operation, this experiment is performed as follows. After Valve 1 and Valve 2 are closed, the same amount of heat is applied from the two heaters to the heated section, while the cooled section is cooled in the water bath. The water temperature, $T_{w}$, is maintained at $20{ }^{\circ} \mathrm{C}$ using the temperature control unit shown in Fig. 3. When the heated section becomes empty, Valve 1 and Valve 2 are opened simultaneously. After $90 \mathrm{sec}$, Valve 1 and Valve 2 are closed simultaneously, and then the same operation is continued. The total heat input from the heaters, $Q$, and the amount of charged working fluid, $V_{0}$, are changed as $Q=400$, $500,600 \mathrm{~W}$ and $V_{0}=0,0.2,0.4, \cdots, 2.0 \mathrm{~L}$, respectively.

Experiment (B) In this experiment, Valve 3 is added on the vapor line as shown in Fig. 2 to change the pressure drop inside the heat pipe intentionally. Except the operation of this valve, the experimental procedure is essentially the same as that of Experiment (A). This experiment is performed under the conditions of $Q=400,500,600 \mathrm{~W}$, $V_{0}=1.0 \mathrm{~L}$ and $T_{w}=20^{\circ} \mathrm{C}$.

\section{RESULTS AND DISCUSSION}

\subsection{Experiment (A)}

The three kinds of pressure differences, $\Delta P_{I}, \Delta P_{I I}, \Delta P_{I I I}$, inside the present heat pipe are defined respectively by the following equations:

$\Delta P_{I}=P_{h}-P_{l, i n}$

$\Delta P_{I I}=P_{l, \text { in }}-P_{l, \text { out }}$

$\Delta P_{I I I}=P_{l, o u t}-P_{r}$

Figure 4 shows the transient variations of the temperatures, $T_{h}, T_{r}$ , $T_{c}$, the pressures, $P_{h}, P_{r}$, and the pressure differences, $\Delta P_{I}, \Delta P_{I I}$, $\Delta P_{I I I}$, inside the heat pipe for (a) $Q=400 \mathrm{~W}, V_{0}=1.0 \mathrm{~L}$ and (b) $Q=$ $600 \mathrm{~W}, V_{0}=1.0 \mathrm{~L}$. The open periods of Valve 1 and Valve 2 are also indicated in the figures. Because Valve 1 and Valve 2 are operated simultaneously, the open periods of the two valves are the same. It is confirmed that the temperatures, the pressures and the pressure differences inside the heat pipe vary cyclically corresponding to the valve operation, and the heat is transported sideward continuously from the heated section to the cooled section. Because the air is evacuated

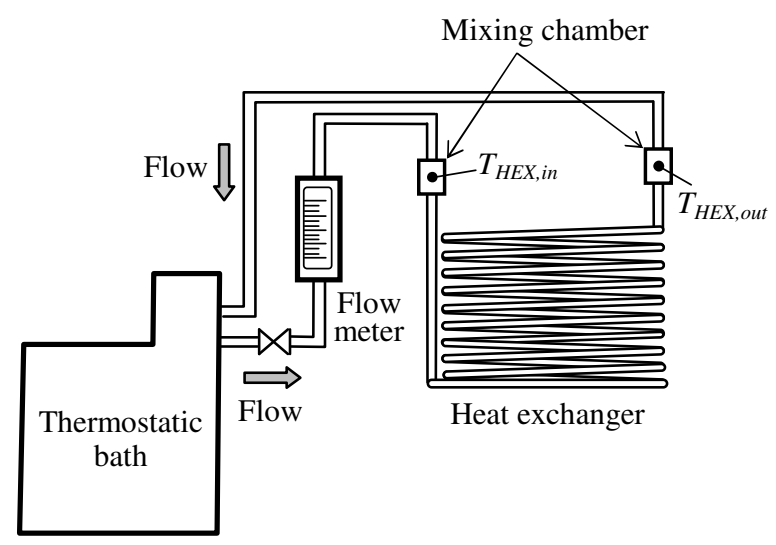

Fig. 3 Temperature control unit

inside the heat pipe, $P_{h}$ and $P_{r}$ correspond to the saturated pressures of $T_{h}$ and $T_{r}$, respectively.

After Valve 1 and Valve 2 are closed, $T_{h}$ and $P_{h}$ increase for a while and the boiling occurs inside the heated section, which is observed through the clear end caps of the heated section. The generated vapor flows sideward through the vapor line to the cooled section, where the heat is discharged into the heat sink. The vapor condenses and the condensate is moreover subcooled in the cooled section. $T_{c}$ is almost equal to $T_{w}$, implying that the condensate is subcooled sufficiently inside the cooled section. The cooled liquid is pushed to the reservoir by the vapor pressure of the working fluid. Because the vapor inside the reservoir is condensed by the incoming cooled liquid, $T_{r}$ and $P_{r}$ decrease gradually during the heat transport period when Valve 1 and Valve 2 are closed. The decreases in $T_{r}$ and $P_{r}$ also cause the decreases in $T_{h}$ and $P_{h}$. When the heated section becomes empty, Valve 1 and Valve 2 are opened simultaneously. The vapor inside the heated section flows into the reservoir, and then the cooled liquid stored inside the reservoir flows down to the heated section under the action of gravity. Resulting from this, the differences in temperature and pressure between the heated section and the reservoir are canceled.

The total pressure difference, $\Delta P_{t}$, inside the heat pipe is expressed as, 


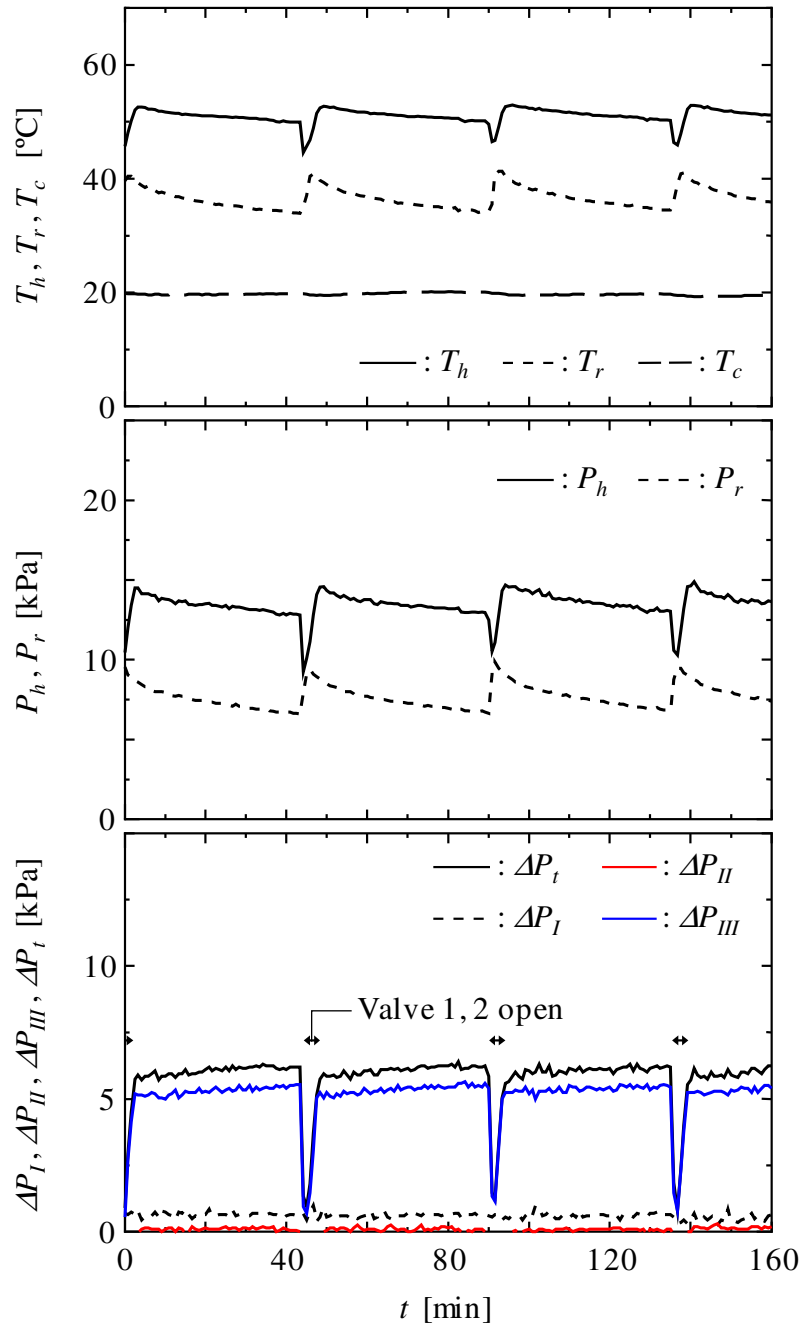

(a) $Q=400 \mathrm{~W}, V_{0}=1.0 \mathrm{~L}$

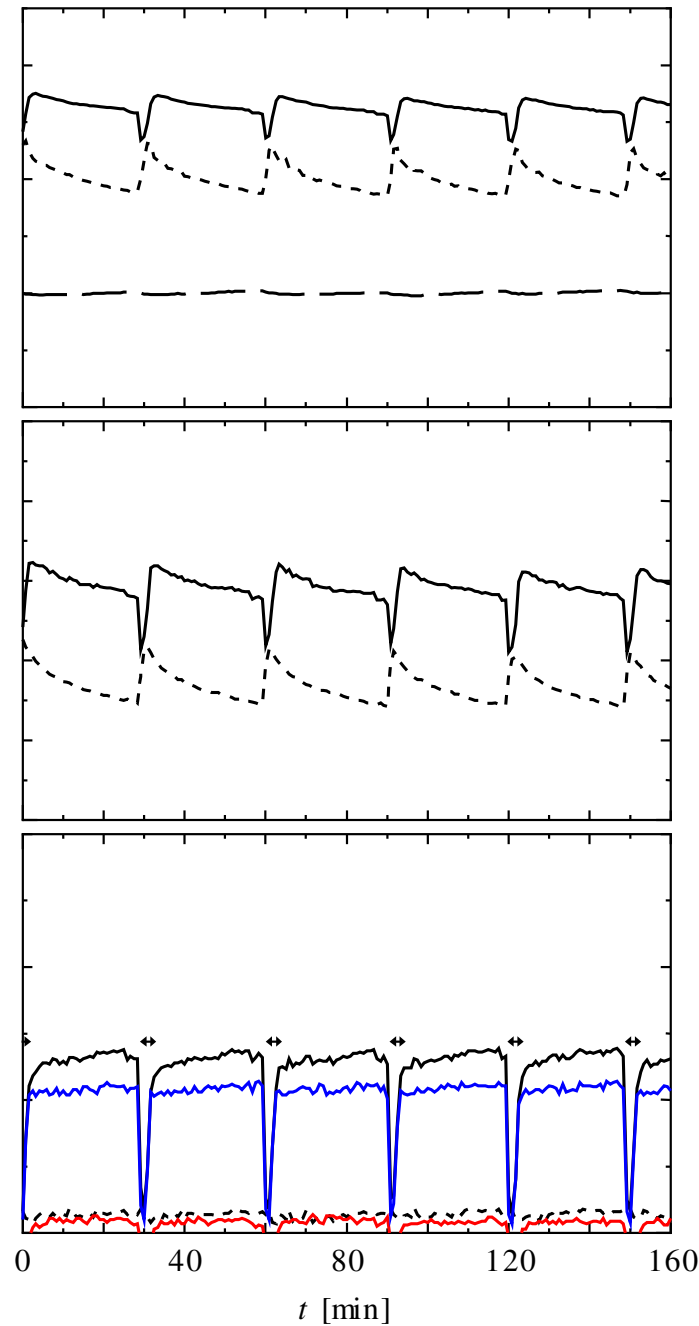

(b) $Q=600 \mathrm{~W}, V_{0}=1.0 \mathrm{~L}$

Fig. 4 Transient variations of temperatures, pressures and pressure differences; experiment (A)

$\Delta P_{t}=\Delta P_{I}+\Delta P_{I I}+\Delta P_{I I I}=P_{h}-P_{r}$

$\Delta P_{t}$ is also shown in Fig. 4. $\Delta P_{t}$ is essentially a driving force to circulate the working fluid and remains almost constant throughout the heat transport cycle except the period when Valve 1 and Valve 2 are opened. It is found that $\Delta P_{I}$ and $\Delta P_{I I}$ are both less than $1.0 \mathrm{kPa}$, implying that the frictional drag is very small between the heated section and the cooled section. $\Delta P_{I I I}$ is the sum of the two pressure drops in the liquid line due to the friction and the gravity. The pressure drop due to the gravity, $\Delta P_{g}$, is expressed as,

$\Delta P_{g}=\rho g H$

where $\rho$ is the liquid density, $g$ the gravitational acceleration and $H$ the difference in height between the vapor-liquid interfaces inside the cooled section and the reservoir. In this experiment, the value of $H$ cannot be obtained exactly because the vapor-liquid interface is invisible inside the cooled section; but the value of $\Delta P_{g}$ is estimated at $3.9 \mathrm{kPa}$ substituting the difference in height $(400 \mathrm{~mm})$ between the heated section and the reservoir for $H$. It is confirmed that $\Delta P_{g}$ is a primary factor dominating $\Delta P_{t}$ in this experiment. It is also revealed that the heat transport cycle becomes faster with the increase in $Q$ because of the increase in the evaporation rate of the working fluid inside the heated section.

The amount of the working fluid which circulates inside the heat pipe, $V_{l}$, is also measured through the clear end caps of the heated section. Figure 5 shows the relation between $V_{0}$ and $V_{l}$ for $Q=400$, $500,600 \mathrm{~W}$. For the case where $V_{0}$ is small, the working fluid does not circulate inside the heat pipe, and thus there exists a minimum value of $V_{0}$ for the heat pipe operation. For the case where $V_{0}$ is greater than the minimum value, $V_{0, \min }, V_{l}$ increases almost linearly with $V_{0}$ and this relation is expressed as,

$V_{l}=V_{0}-0.53 \quad\left(V_{0, \min } \leq V_{0} \leq V_{0, \max }\right)$

where $V_{0, \max }$ is the maximum value of $V_{0}$, which depends on the inner volume of the heat pipe. $V_{0, \max }$ is $2.1 \mathrm{~L}$ for the present heat pipe. Equation (7), which is also shown in Fig. 5, implies that about $0.53 \mathrm{~L}$ of the working fluid is stagnant inside the heat pipe including the liquid line $(0.084 \mathrm{~L})$ and the cooled section $(0.38 \mathrm{~L})$.

Figure 6 shows the average temperatures of the heated section, $T_{h, \text { ave }}$, and the reservoir, $T_{r \text {,ave }}$, during the heat transport period when Valve 1 and Valve 2 are closed. With the increase in $V_{0}$, the amount 


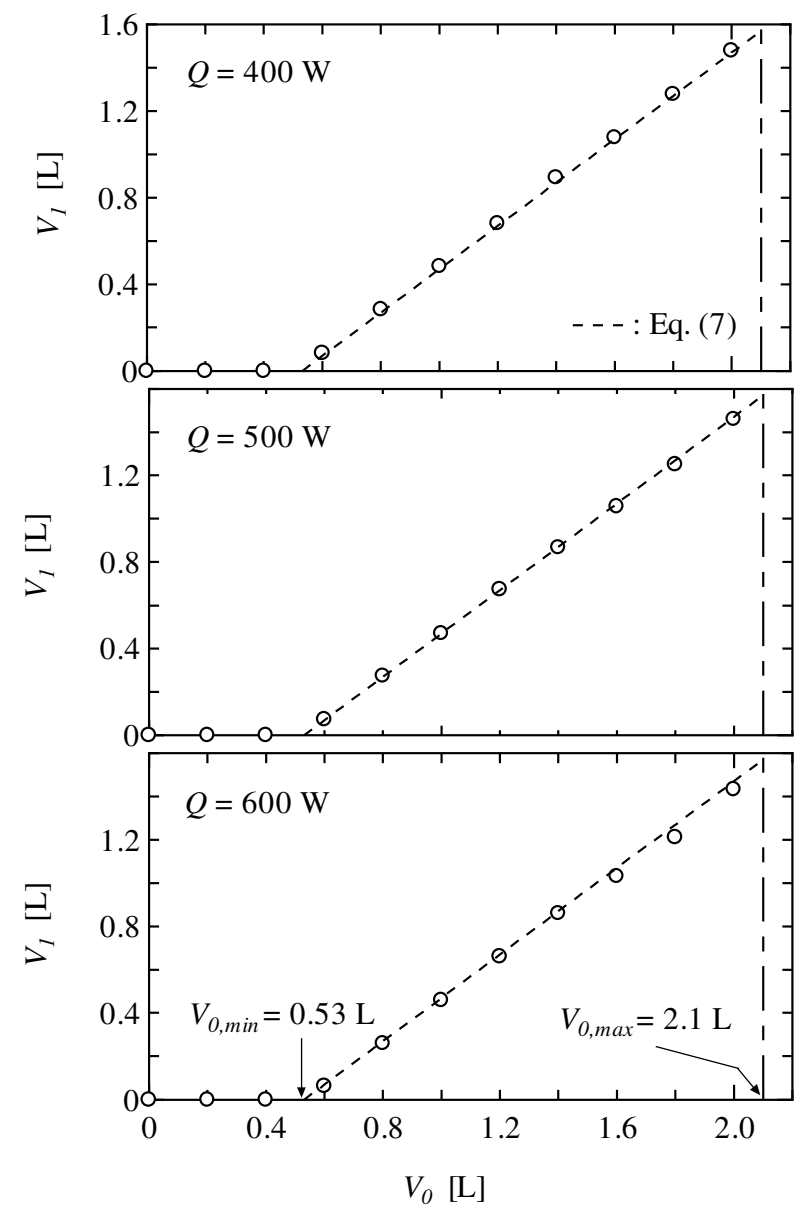

Fig. 5 Amount of working fluid which circulates inside heat pipe

of the cooled liquid stored inside the reservoir is increased and the condensation of vapor inside the reservoir is enhanced, resulting in the decrease in $T_{r, \text { ave }}$ and $T_{h, \text { ave }}$.

Figure 7 shows the relation between the heat input, $\Phi_{i n}$, and the heat output, $\Phi_{\text {out }}$, of the heat pipe. $\Phi_{\text {in }}$ and $\Phi_{\text {out }}$ are expressed respectively as,

$\Phi_{i n}=Q$

$\Phi_{\text {out }}=\frac{m c \int_{t_{\text {cycle }}}\left(T_{H E X, \text { out }}-T_{H E X, \text { in }}\right) d t}{t_{\text {cycle }}}$

where $m$ and $c$ are the mass flow rate and the specific heat respectively of the liquid inside the heat exchanger shown in Fig. 3, and $t_{c y c l e}$ is the time of one heat transport cycle. It is shown that more than $91 \%$ of the heat is transported from the heated section to the cooled section with the heat loss less than $9.0 \%$, which confirms the effectiveness of the present heat pipe for the sideward heat transport.

\subsection{Experiment (B)}

Figure 8 shows the transient variations of the temperatures, $T_{h}, T_{r}, T_{c}$, the pressures, $P_{h}, P_{r}$, and the pressure differences, $\Delta P_{I}, \Delta P_{I I}, \Delta P_{I I I}$, inside the heat pipe for $Q=500 \mathrm{~W}, V_{0}=1.0 \mathrm{~L}$ having the pressure drops of maximum (a) $0.3 \mathrm{kPa}$, (b) $5.0 \mathrm{kPa}$ and (c) $10 \mathrm{kPa}$ respectively inside the vapor line. $\Delta P_{I I}$ corresponds to this pressure drop, which is intentionally made by using Valve 3 . The open periods of Valve 1 and

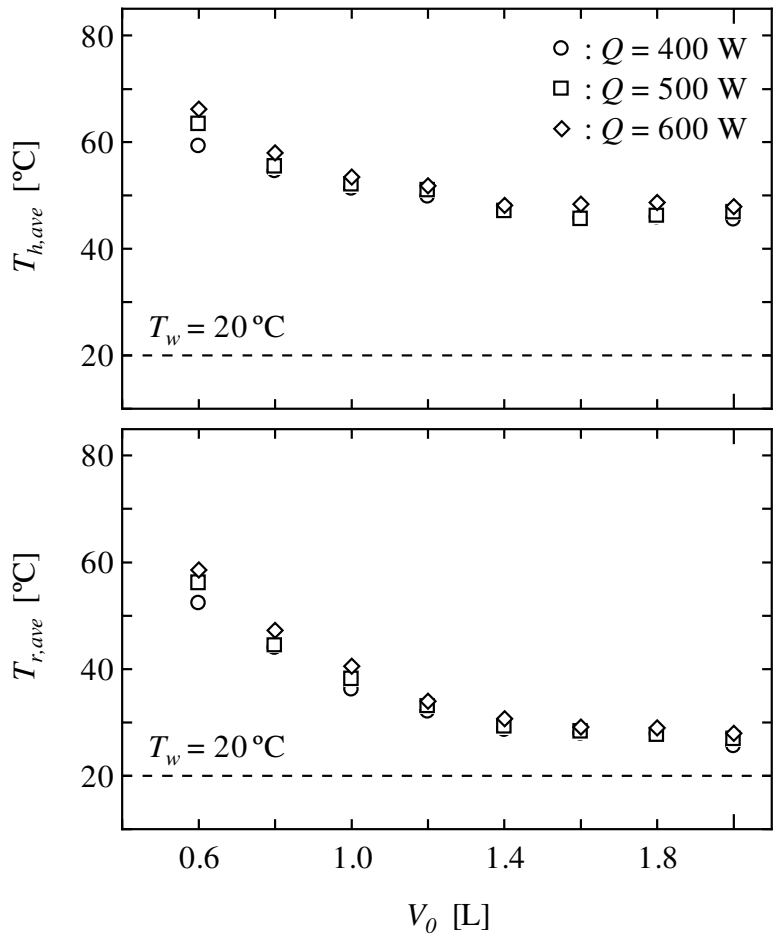

Fig. 6 Average temperatures of heated section and reservoir

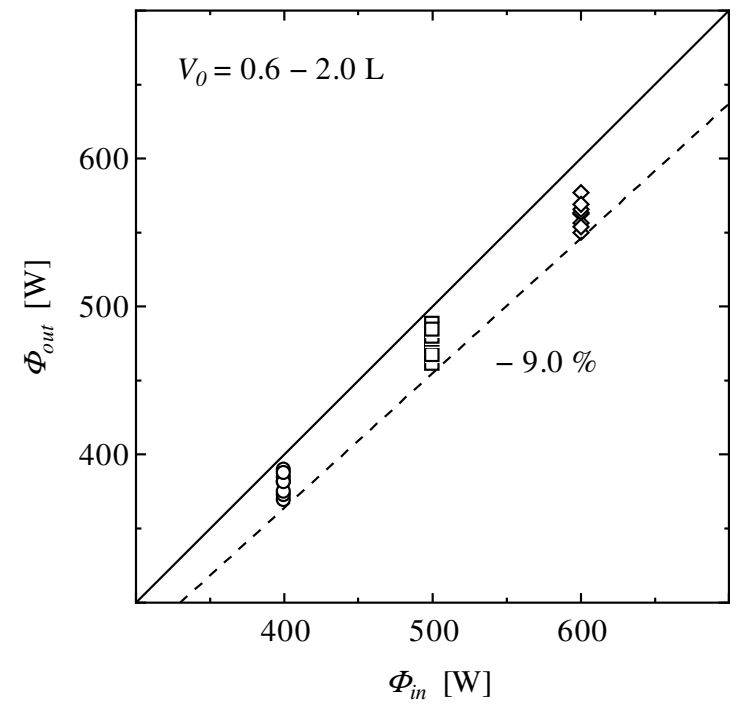

Fig. 7 Relation between heat input and heat output

Valve 2 are also indicated in the figures. Regardless of the pressure drop, it is confirmed that the heat pipe works periodically corresponding to the operations of Valve 1 and Valve 2, and the heat is transported sideward continuously from the heated section to the cooled section. However, it is revealed that the pressure drop greatly affects the transient variations of the temperatures and the pressures inside the heat pipe. The temperature and the pressure not only inside the heated section but also inside the reservoir become higher with the increase in the pressure drop in the vapor line. This is due to the increase in 


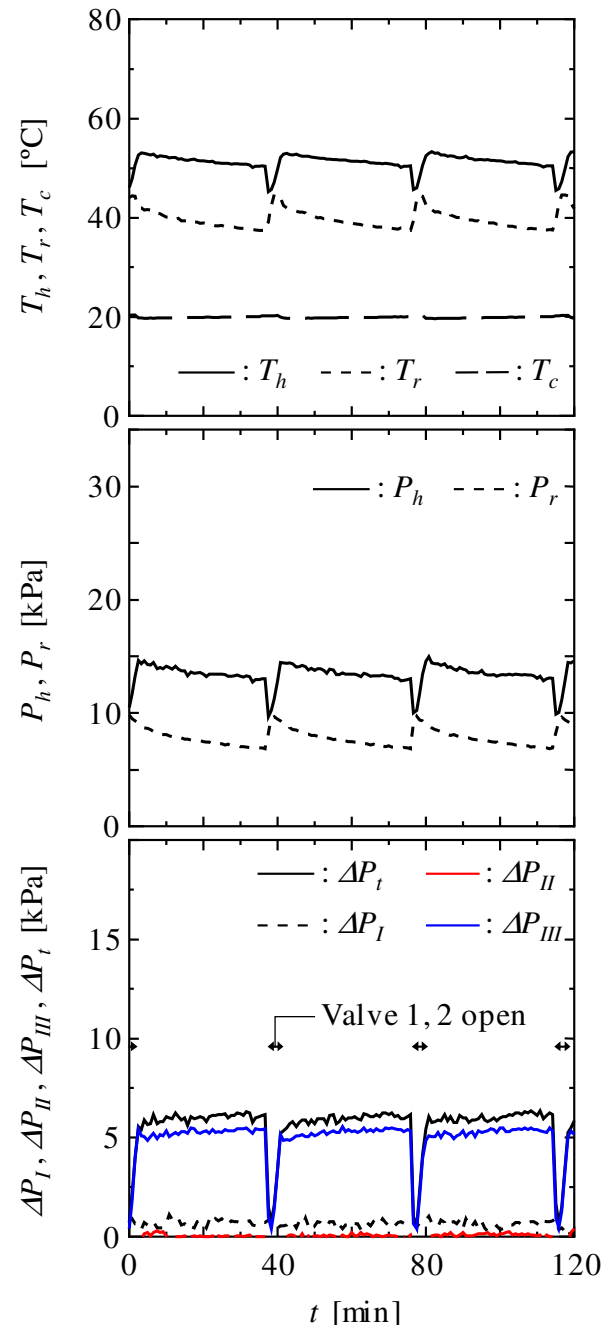

(a) $\Delta P_{I I} \approx 0.3 \mathrm{kPa}$

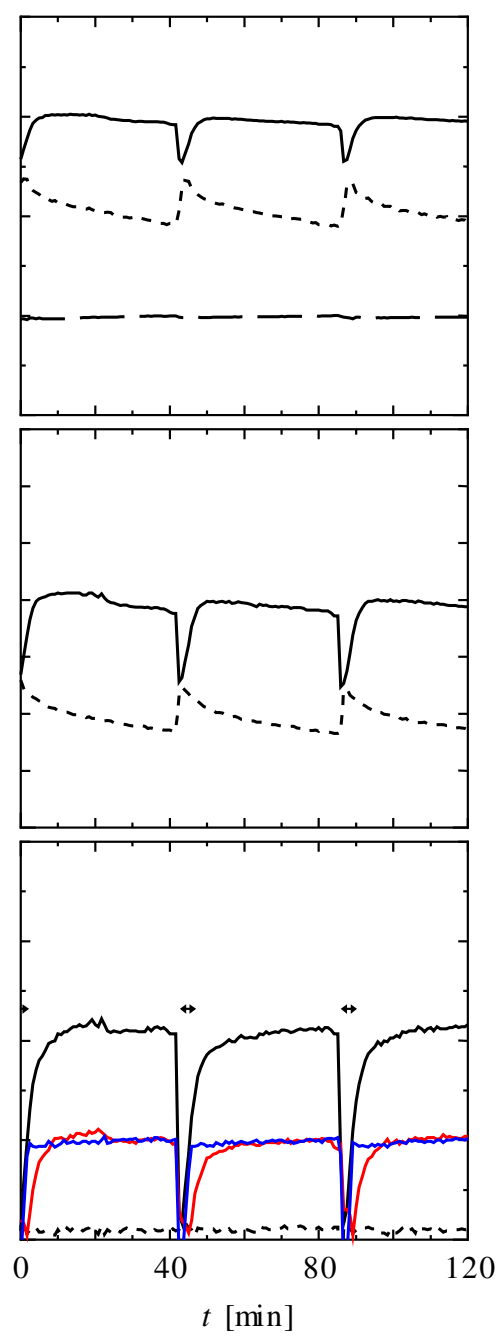

(b) $\Delta P_{I I} \approx 5.0 \mathrm{kPa}$

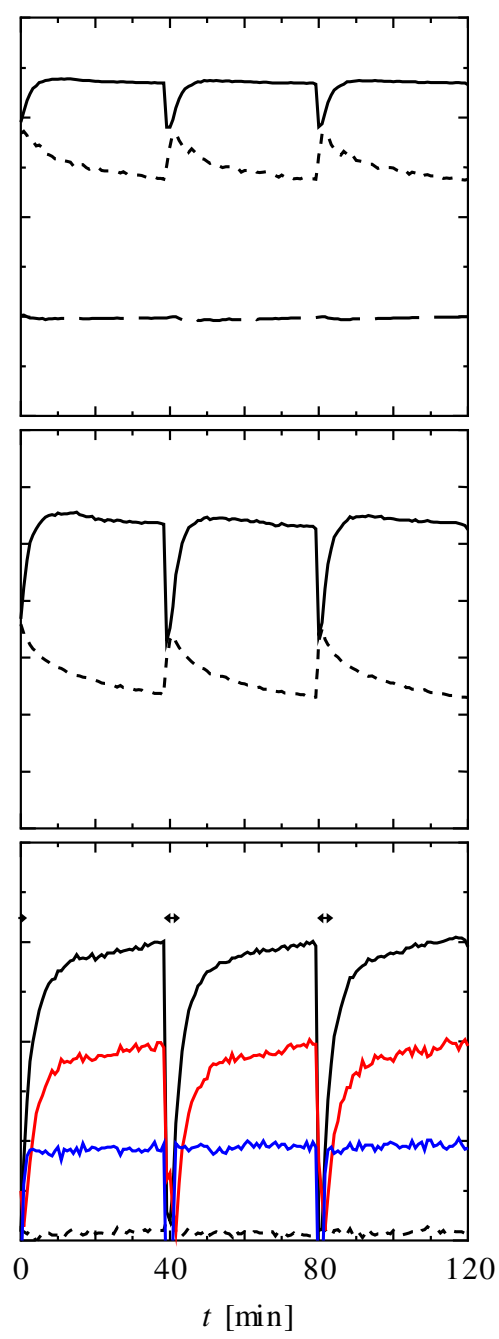

(c) $\Delta P_{I I} \approx 10 \mathrm{kPa}$

Fig. 8 Transient variations of temperatures, pressures and pressure differences; experiment (B), $Q=500 \mathrm{~W}, V_{0}=1.0 \mathrm{~L}$

temperature of the vapor flowing into the reservoir when Valve 1 and Valve 2 are opened. The present heat pipe enables to transport the heat over a long distance. Moreover, in a practical application, the vapor and liquid lines can be bent without any difficulty. However, the pressure drop is an important consideration for the design of the present heat pipe.

\section{CONCLUSIONS}

For the purse of the sideward heat transport over a long distance, the vapor-pressure-driven heat pipe is devised and its operational characteristics are experimentally investigated. It is confirmed that the heat pipe works periodically corresponding to the valve operation, and the heat is transported sideward continuously from the heated section to the cooled section. Effect of the amount of the working fluid on the operational characteristics of the heat pipe is also revealed. The circulation of the working fluid inside the heat pipe is ensured even when the heat transport distance is very long. Therefore, the present heat pipe enables to transport the heat over a long distance. Moreover, in a practical application, the vapor and liquid lines can be bent without any difficulty. However, the pressure drop is an important consideration for the design of the present heat pipe. The vaporpressure-driven heat pipe is effective for a large-scale thermal management.

\section{ACKNOWLEDGEMENTS}

This work was supported by Grant-in-Aid for Young Scientists (B), No. 20760138, from the Ministry of Education, Culture, Sports, Science and Technology, Japan.

\section{NOMENCLATURE}

c specific heat $(\mathrm{J} / \mathrm{kg} \cdot \mathrm{K})$

$g \quad$ gravitational acceleration $\left(\mathrm{m} / \mathrm{s}^{2}\right)$

$H \quad$ height (m)

$m \quad$ mass flow rate $(\mathrm{kg} / \mathrm{s})$

$P_{c} \quad$ vapor pressure inside cooled section $(\mathrm{kPa})$

$P_{h} \quad$ vapor pressure inside heated section $(\mathrm{kPa})$

$P_{l} \quad$ vapor pressure inside vapor line $(\mathrm{kPa})$

$P_{r} \quad$ vapor pressure inside reservoir $(\mathrm{kPa})$

$Q \quad$ heat input (W) 
$T_{c} \quad$ liquid temperature inside cooled section $\left({ }^{\circ} \mathrm{C}\right)$

$T_{H E X} \quad$ liquid temperature inside heat exchanger $\left({ }^{\circ} \mathrm{C}\right)$

$T_{h} \quad$ liquid temperature inside heated section $\left({ }^{\circ} \mathrm{C}\right)$

$T_{r} \quad$ liquid temperature inside reservoir $\left({ }^{\circ} \mathrm{C}\right)$

$T_{w} \quad$ water temperature $\left({ }^{\circ} \mathrm{C}\right)$

$t_{\text {cycle }} \quad$ time of one heat transport cycle (s)

$V_{0} \quad$ amount of working fluid charged inside heat pipe (L)

$V_{l} \quad$ amount of working fluid which circulates inside heat pipe (L)

$\begin{array}{ll}\text { Greek Symbols } \\ \Delta P & \text { pressure difference }(\mathrm{kPa}) \\ \Phi & \text { heat input, heat output }(\mathrm{W}) \\ \rho & \text { density }\left(\mathrm{kg} / \mathrm{m}^{3}\right) \\ \text { Subscripts } & \\ \text { I, II, III } & \text { sections of I, II, III } \\ \text { ave } & \text { average } \\ g & \text { gravity } \\ \text { in } & \text { inlet, input } \\ \text { max } & \text { maximum } \\ \text { min } & \text { minimum } \\ \text { out } & \text { outlet, output } \\ t & \text { total }\end{array}$

\section{REFERENCES}

Basiulis, A., Fleischman, G. L., and Minning, C. P., 1980, "Design, Development, and Test of a 1000W Osmotic Heat Pipe," Proceedings of the AIAA 15th Thermophysics Conference, Snowmass, CO, 324-344.

Chisholm, D., 1974, "The Anti-gravity Thermosyphon," Multi-phase Flow Systems, 2, I. Chem. E. Symp. Ser. No. 38, 1-17.

Fantozzi, F., Filippeschi, S., Sasin, V. J., and Savchenkova, N. M., 2002, "Heat Transport Device Based on Pulsing Thermosyphons with Forced Fluctuations of Pressure", Proceedings of the 12th International Heat Pipe Conference, Moscow, Russia, 469-474.

Fantozzi, F., Filippeschi, S., and Latrofa, E. M., 2004, "Upward and Downward Heat and Mass Transfer with Miniature Periodically Operating Loop Thermosyphons," Superlattices and Microstructures, 35 (3-6), 339-351.

doi:10.1016/j.spmi.2004.01.007

Filippeschi, S., 2006, "On Periodic Two-phase Thermosyphons Operating against Gravity," International Journal of Thermal Sciences, 45 (2), 124-137.

doi:10.1016/j.ijthermalsci.2005.06.008

Gondipalli, S., Sammakia, B., Bhopte, S., Schmidt, R., Iyengar, M. K., and Murray, B., 2009, "Optimization of Cold Aisle Isolation Designs for a Data Center with Roofs and Doors Using Slits," IPACK200989203, Proceedings of the ASME 2009 InterPACK Conference, San Francisco, CA.
Hashimoto, N., Kawabata, K., and Kamiya, Y., 1995, “Top Heat Type Heat Pipe," Proceedings of the 9th International Heat Pipe Conference, Albuquerque, NM, 833-837.

Hirashima, M., Kimura, K., Utsumi, Y., Kimura, K., and Negishi, K., 1993, "Experimental Study of Top Heat Mode Thermosyphon (On the Lifting Mechanism of Working Fluid Effects on the Extension of Stable Working Range), Trans. of the JAR, 10 (2), 247-256 (in Japanese).

Imura, H., Koito, Y., and Ichinomiya, T., 2003, "An Anti-gravity Thermosyphon with a Switching Valve," Proceedings of the 7th International Heat Pipe Symposium, Jeju, Korea, 83-87.

Kadoguchi, K., and Yamazaki, M., 2004, "Intermittent Heat Transportation by Discharge of Accumulated Vapor," Applied Thermal Engineering, 24 (17-18), 2761-2775. doi:10.1016/j.applthermaleng.2004.03.021

Karajgikar, S., Mulay, V., Agonafer, D., and Schmidt, R., 2009, "Cooling of Data Centers Using Airside Economizers," IPACK200989356, Proceedings of the ASME 2009 InterPACK Conference, San Francisco, CA.

Kawabata, K., Hashimoto N., and Kamiya, Y., 1996, "Anti-gravity Heat Pipe," Proceedings of the 5th International Heat Pipe Symposium, Melbourne, Australia, 168-175.

Maydanik, Yu. F., 2005, "Loop Heat Pipes," Applied Thermal Engineering, 25 (5-6), 635-657. doi:10.1016/j.applthermaleng.2004.07.010

Minning, C. P., Fleischman, G. L., and Giants, T. W., 1978, "Development of an Osmotic Heat Pipe," Proceedings of the 3rd International Heat Pipe Conference, Palo Alto, CA, 327-334.

Minning, C. P., Fleischman, G. L., Anderson, R. A., and Perrygo, C. M., 1979, "Design and Test of a Prototype Osmotic Heat Pipe," Proceedings of the AIAA 14th Thermophysics Conference, Orlando, FL, 307-328.

Mochizuki, M., Nguyen, Th., Mashiko, K., Saito, Y., Nguyen, Ti., and Wuttijumnong, V., 2010, "Challenges of Heat Pipe Application for Global Warming," Proceedings of the 15th International Heat Pipe Conference, Clemson, SC (in press).

Ogushi, T., Murakami, M., and Yamanaka, G., 1986, "Study of a Downward Heat Transport Device Utilizing Vapor Pressure as the Liquid Pumping Force (1st Report, The Analysis of the Static Characteristics)," Trans. of the JSME, Ser. B, 52 (481), 3348-3352 (in Japanese).

Patterson, M. K., Atwood, D., and Miner, J. G., 2009, "Evaluation of Air-side Economizer Use in a Compute-intensive Data Center," IPACK2009-89358, Proceedings of the ASME 2009 InterPACK Conference, San Francisco, CA. 